\title{
Low bone mineral density is associated with global coronary atherosclerotic plaque burden in stable angina patients
}

This article was published in the following Dove Press journal:

Clinical Interventions in Aging

\author{
Xue-qiang Guan' \\ Yang-jing $\mathrm{Xue}^{2}$ \\ Jie Wang ${ }^{2}$ \\ Jun $\mathrm{Ma}^{2}$ \\ Yue-chun $\mathrm{Li}^{2}$ \\ Cheng Zheng ${ }^{2}$ \\ Sai-zhu Wu'
}

'Department of Cardiology, Nanfang Hospital, Southern Medical University,

Guangzhou, People's Republic of

China; ${ }^{2}$ Department of Cardiology,

Second Affiliated Hospital of Wenzhou

Medical University, Wenzhou, People's

Republic of China
Correspondence: Sai-zhu Wu

Department of Geriatrics, Nanfang Hospital, Southern Medical University,

1838 Guangzhou Dadao Bei, Guangzhou, 510000 , People's Republic of China

Tel +860206278 I2I I

Email wusaizhu_nfdx@I63.com
Background: Accelerated atherosclerosis is considered to be the linking factor between low bone mineral density (BMD) and increased cardiovascular events and mortality, while some coronary angiographic studies do not support this point. In this study, we attempt to provide a distinct comprehensive view of the relationship between BMD and the angiographically determined coronary atherosclerotic burden.

Methods: A total of 459 consecutive patients with stable chest pain suspected of coronary artery disease (CAD) underwent both dual-energy X-ray absorptiometry scan and selective coronary angiography. The association between BMD and global coronary atherosclerotic plaque burden as represented by the multivessel involvement and the modified Gensini score was analyzed.

Results: Multivariable analysis revealed that the low BMD at femoral neck and total hip was an independent correlate of multivessel CAD. The $T$-scores measured at femoral neck and total hip were both negatively and independently associated to the modified Gensini score. These inversely correlated relationships between BMD and CAD were not observed at lumbar spine 1-4.

Conclusion: This cross-sectional study elucidated an inverse relationship between hip BMD and the modified Gensini score, and low hip BMD values ( $T$-scores) were significantly and independently associated with increased risk of multivessel coronary disease in patients hospitalized for stable chest pain.

Keywords: coronary artery disease, bone mineral density, global coronary atherosclerotic plaque burden, modified Gensini score

\section{Introduction}

Many longitudinal cohort studies have indicated that low bone mineral density (BMD) is independently associated with higher cardiovascular events and mortality. ${ }^{1-6}$ There is an increased incidence of cardiac death, myocardial infarction (MI), and stroke in older patients with low BMD at their baseline examination. Although the potential mechanisms underpinning the link between the two conditions are not clear yet, a growing literature has revealed that atherosclerosis and bone demineralization share common pathophysiological mechanisms. ${ }^{7-9}$ Thus, a rational hypothesis is that accelerated atherosclerosis links low BMD and increased cardiovascular events and mortality. ${ }^{10}$ However, the results from cross-sectional studies assessing the relationship between BMD and coronary angiographic findings were inconsistent and challenged the hypothesis. ${ }^{11-14}$ Their data show that low BMD is not related to angiographically determined coronary artery disease $(\mathrm{CAD})$ and speculate that low BMD is more strongly associated with the plaque instability and thrombosis precipitating the acute atherothrombotic coronary event than with coronary atherosclerosis per se. ${ }^{11}$ 
The traditional angiographic definition of CAD adopted by the aforementioned coronary angiographic studies, however, does not accurately reflect the extent of atherosclerosis of the whole coronary tree and is unable to reliably predict future coronary events. ${ }^{15,16}$ Thus, in the present study, we investigated the relationship between BMD and global coronary atherosclerotic plaque burden instead of the severity of a coronary stenosis. In this way, a more comprehensive understanding of the correlation between low BMD and angiographic coronary atherosclerosis was presented.

\section{Methods}

\section{Study population}

A total of 519 patients with stable suspected CAD undergoing selective coronary angiography (CAG) from December 2012 to February 2014 were consecutively recruited. Any patient with ST elevation MI, non-ST elevation MI, unstable angina, previously coronary angiographically confirmed CAD, or a history of revascularization was excluded from the study. To avoid confounding variables for BMD, we excluded individuals with heart failure with reduced left ventricular ejection fraction $(<50 \%)$ or renal failure $(45)$, hyperparathyroidism or thyroid diseases (six), taking medications with skeletal effects within 12 months (eg, steroids or estrogens or bisphosphonates) (six), or with incorrect BMD acquisition or reporting (three). In total, 459 subjects were finally eligible for analysis in our study.

Demographic data and information on cardiovascular risk factors were obtained by a standardized interview before the CAG. Smoking status was self-reported. Hypertension was defined as experiencing systolic blood pressure $\geq 140 \mathrm{mmHg}$ and/or diastolic blood pressure $\geq 90 \mathrm{mmHg}$ and/or receiving treatment for hypertension. Diabetes was defined as either having a fasting plasma glucose $\geq 7.1 \mathrm{mmol} / \mathrm{L}$ or using hypoglycemic medications. Hypercholesterolemia was defined as presenting a total cholesterol $\geq 5.72 \mathrm{mmol} / \mathrm{L}$ and/or a low-density lipoprotein cholesterol $\geq 3.64 \mathrm{mmol} / \mathrm{L}$ and/or receiving treatment for hypercholesterolemia. Body mass index (BMI) was calculated as weight $(\mathrm{kg})$ divided by height $\left(\mathrm{m}^{2}\right)$.

The study protocol was approved by the institutional review board of Wenzhou Medical University and complied with the Declaration of Helsinki. Written informed consent was obtained from each patient enrolled in the study.

\section{Coronary angiograms and scoring}

CAG was performed using standard Judkin's techniques for all the patients. The percentages of lumen diameter stenosis were assessed by visual analyses. CAD was defined as $\mathrm{a} \geq 50 \%$ luminal diameter narrowing of a major epicardial artery or the left main coronary artery. Multivessel CAD was defined as a $\geq 50 \%$ diameter stenosis in at least two major epicardial vessels or the left main coronary artery.

The modified Gensini score has been described and validated previously. ${ }^{17,18}$ The most severe stenosis in each of eight coronary segments was graded from 1 to 4 (1: $1 \%-49 \%$ lumen diameter reduction, $2: 50 \%-74 \%$ stenosis, 3: 75\%-99\% stenosis, $4: 100 \%$ occlusion) to give a total score of between 0 and 32 .

The angiographic images were reviewed by two experienced cardiologists who were blinded to the BMD results, and the modified Gensini score of every patient was recorded according to the consensus opinion of them.

\section{BMD measurement}

BMD $\left(\mathrm{g} / \mathrm{cm}^{2}\right)$ was measured on the same day of admission by dual-energy X-ray absorptiometry at the lumbar spine (L1-L4) and the hip using GE Lunar Prodigy and described as $T$-score and $Z$-score. BMD scans were independently analyzed by two experienced researchers. Calibration was performed daily on a single anthropomorphic phantom. The coefficient of variation used for precise assessment of the BMD measurement was $1.2 \%$ for the total hip, $1.4 \%$ for the femoral neck, and $1.0 \%$ for the lumbar spine. In accordance with World Health Organization (WHO) criteria (Genant, Cooper et al 1999), ${ }^{19}$ BMD results were classified into three groups as normal ( $T$-score $\geq-1.0 \mathrm{SD}$ ), osteopenia ( $T$-score -1.0 to $-2.5 \mathrm{SD}$ ), and osteoporosis ( $T$-score $\leq-2.5 \mathrm{SD}$ ). In the present study, low BMD group consisted of osteopenia and osteoporosis.

\section{Statistical analysis}

Continuous variables are expressed as mean and SD as indicated and compared using Student's $t$-test or Wilcoxon rank-sum test if applicable. Discrete variables are presented as numbers and percentages and compared with the $\chi^{2}$ test, unless the observation in any cell was $<5$, in which case Fisher's exact test was used. One-way analysis of variance was performed to analyze the patient demographics in three groups in Table 1.

We selected these potential confounders on the basis of their associations with the outcomes of interest or a change in effect estimate of $>10 \%$ or $P$-values $<0.1$ in univariable analyses. Multivariable logistic regression analyses were used to determine the relationship between BMD and the multivessel CAD (Table 2). 
Table I Demographic characteristics of the patients

\begin{tabular}{|c|c|c|c|c|}
\hline \multirow[t]{2}{*}{ Parameters } & \multirow{2}{*}{$\begin{array}{l}\text { Non-CAD } \\
n=224\end{array}$} & \multicolumn{2}{|l|}{ CAD } & \multirow[t]{2}{*}{$P$-value } \\
\hline & & One-vessel $(n=108)$ & Multivessel $(n=127)$ & \\
\hline Age (years) & $62.03 \pm 10.16$ & $65.93 \pm 9.16$ & $68.47 \pm 8.12$ & $<0.001$ \\
\hline Men, n (\%) & $105(46.88 \%)$ & $61(56.48 \%)$ & 81 (63.78\%) & 0.008 \\
\hline BMI $\left(\mathrm{kg} / \mathrm{m}^{2}\right)$ & $24.26 \pm 3.35$ & $24.92 \pm 3.78$ & $24.36 \pm 3.14$ & 0.242 \\
\hline Smoker, n (\%) & $62(27.68 \%)$ & $4 \mathrm{l}(37.96 \%)$ & $62(48.82 \%)$ & $<0.001$ \\
\hline Hypertension, n (\%) & 139 (62.05\%) & $82(75.93 \%)$ & 107 (84.25\%) & $<0.001$ \\
\hline Diabetes & 40 (I7.86\%) & $28(25.93 \%)$ & $44(34.65 \%)$ & 0.002 \\
\hline Hypercholesterolemia, n (\%) & $57(25.45 \%)$ & $29(26.85 \%)$ & $43(33.86 \%)$ & 0.229 \\
\hline $\mathrm{Cr}(\mu \mathrm{mol} / \mathrm{L})$ & $73.56 \pm 23.29$ & $78.54 \pm 26.33$ & $84.28 \pm 40.86$ & 0.005 \\
\hline Modified Gensini score & $5.26 \pm 1.27$ & $7.93 \pm 1.42$ & $12.26 \pm 3.62$ & $<0.001$ \\
\hline Femoral neck $\left(\mathrm{g} / \mathrm{cm}^{2}\right)$ & $0.86 \pm 0.15$ & $0.84 \pm 0.15$ & $0.79 \pm 0.13$ & $<0.001$ \\
\hline Femoral neck $T$-score (SD) & $-1.33 \pm 1.08$ & $-1.57 \pm 0.99$ & $-2.03 \pm 0.93$ & $<0.001$ \\
\hline Femoral neck Z-score (SD) & $-0.06 \pm 0.92$ & $-0.11 \pm 0.91$ & $-0.43 \pm 0.83$ & $<0.001$ \\
\hline Total hip $\left(\mathrm{g} / \mathrm{cm}^{2}\right)$ & $0.95 \pm 0.15$ & $0.92 \pm 0.16$ & $0.87 \pm 0.14$ & $<0.001$ \\
\hline Total hip T-score (SD) & $-0.75 \pm 1.07$ & $-0.99 \pm 1.05$ & $-1.43 \pm 0.97$ & $<0.001$ \\
\hline Total hip Z-score (SD) & $0.20 \pm 0.93$ & $0.15 \pm 0.95$ & $-0.18 \pm 0.86$ & $<0.001$ \\
\hline Lumbar spine $\left(\mathrm{g} / \mathrm{cm}^{2}\right)$ & $1.04 \pm 0.20$ & $1.02 \pm 0.22$ & $1.01 \pm 0.21$ & 0.567 \\
\hline Lumbar spine $T$-score (SD) & $-1.33 \pm 1.61$ & $-1.48 \pm 1.73$ & $-1.58 \pm 1.65$ & 0.380 \\
\hline Lumbar spine Z-score (SD) & $-0.3 I \pm 1.32$ & $-0.33 \pm 1.52$ & $-0.31 \pm 1.39$ & 0.992 \\
\hline Minimum $T$-score (SD) & $-1.81 \pm 1.20$ & $-2.04 \pm 1.20$ & $-2.37 \pm 1.0 \mathrm{I}$ & $<0.001$ \\
\hline Minimum Z-score (SD) & $-0.66 \pm 1.01$ & $-0.74 \pm 1.09$ & $-0.88 \pm 0.87$ & 0.139 \\
\hline
\end{tabular}

Notes: Demographics were analyzed by one-way analysis of variance, and values are presented as means \pm SD. Percentages do not sum to I00 because of rounding.

Abbreviations: BMI, body mass index; CAD, coronary artery disease; $\mathrm{Cr}$, creatinine.

In order to determine whether BMD (per SD of $T$-score) was associated with the modified Gensini score, multivariable linear regression analyses were used and adjusted for known or potentially important confounders (Table 3).

A $P$-value $<0.05$ was considered statistically significant. All analyses were performed using Empower ${ }^{\circledR}$ (Www. empowerstats.com; X\&Y Solutions, Inc., Boston, MA, USA) and R (http://www.R-project.org).

\section{Results}

\section{Characteristics of study population}

Our study population $(\mathrm{n}=459)$ included 212 women and 247 men, with an average age of $64.73 \pm 9.79$ years. The vast majority of women (206 of $212,97 \%$ ) were postmenopausal women, and $92 \%$ of men (227 of 247) were older than 50 years. According to the minimum $T$-value of the measured sites, 159 patients (54 men, 105 women)

Table 2 Association between low BMD at various skeletal regions and multivessel CAD

\begin{tabular}{|c|c|c|c|c|c|c|c|c|}
\hline \multirow{2}{*}{$\frac{\text { Variables }}{\text { BMD }}$} & \multirow[t]{2}{*}{$\mathbf{n}$} & \multirow{2}{*}{$\begin{array}{l}\text { Mean } \pm \text { SD } \\
\left(\mathrm{g} / \mathrm{cm}^{2}\right)\end{array}$} & \multicolumn{3}{|c|}{ Crude } & \multicolumn{3}{|c|}{ Adjusted } \\
\hline & & & OR & $95 \% \mathrm{Cl}$ & P-value & OR & $95 \% \mathrm{Cl}$ & P-value \\
\hline \multicolumn{9}{|c|}{ Multivessel CAD vs non-multivessel CAD } \\
\hline \multicolumn{9}{|l|}{ Femoral neck } \\
\hline Normal ( $T$-score $\geq-I .0 \mathrm{SD})$ & 129 & $1.00 \pm 0.10$ & I & & & I & & \\
\hline Osteopenia ( $T$-score -1.0 to $-2.5 \mathrm{SD})$ & 236 & $0.82 \pm 0.06$ & 2.83 & I.59-5.07 & $<0.001$ & 2.84 & $1.52-5.30$ & 0.001 \\
\hline Osteoporosis ( $T$-score $\leq-2.5 \mathrm{SD})$ & 94 & $0.65 \pm 0.07$ & 4.67 & $2.43-8.99$ & $<0.001$ & 4.34 & $2.05-9.20$ & $<0.001$ \\
\hline \multicolumn{9}{|l|}{ Total hip } \\
\hline Normal ( $T$-score $\geq-I .0 \mathrm{SD})$ & 234 & $1.03 \pm 0.12$ & 1 & & & I & & \\
\hline Osteopenia ( $T$-score -1.0 to $-2.5 \mathrm{SD})$ & 182 & $0.84 \pm 0.06$ & 3.03 & $1.93-4.77$ & $<0.001$ & 2.55 & $1.56-4.17$ & $<0.001$ \\
\hline Osteoporosis ( $T$-score $\leq-2.5 \mathrm{SD})$ & 43 & $0.66 \pm 0.05$ & 3.17 & $1.58-6.38$ & 0.001 & 2.91 & $1.29-6.60$ & 0.010 \\
\hline \multicolumn{9}{|l|}{ Lumbar spine } \\
\hline Normal ( $T$-score $\geq-I .0 \mathrm{SD})$ & 174 & $1.23 \pm 0.14$ & I & & & I & & \\
\hline Osteopenia ( $T$-score -1.0 to $-2.5 \mathrm{SD})$ & 155 & $0.99 \pm 0.07$ & $\mathrm{I} .07$ & $0.65-1.74$ & 0.800 & 1.05 & $0.61-1.82$ & 0.858 \\
\hline Osteoporosis ( $T$-score $\leq-2.5 \mathrm{SD})$ & 130 & $0.79 \pm 0.08$ & 1.27 & $0.77-2.11$ & 0.346 & 1.33 & $0.71-2.48$ & 0.380 \\
\hline
\end{tabular}

Note: Relationship was determined by multivariable logistic regression analysis.

Abbreviations: BMD, bone mineral density; CAD, coronary artery disease. 
Table 3 Association between $T$-score at various skeletal regions and the modified Gensini score

\begin{tabular}{|c|c|c|c|c|c|c|c|c|}
\hline \multirow{2}{*}{$\begin{array}{l}\text { Variables } \\
\text { BMD }\end{array}$} & \multirow[t]{2}{*}{$\bar{n}$} & \multirow{2}{*}{$\begin{array}{l}\text { Mean } \pm \text { SD } \\
\left(\mathrm{g} / \mathrm{cm}^{2}\right)\end{array}$} & \multicolumn{3}{|c|}{ Crude } & \multicolumn{3}{|c|}{ Adjusted } \\
\hline & & & $\bar{\beta}$ & SE & $P$-value & $\beta$ & SE & $P$-value \\
\hline Femoral neck & 459 & $0.83 \pm 0.14$ & -1.39 & 0.15 & $<0.001$ & -1.13 & 0.15 & $<0.001$ \\
\hline \multicolumn{9}{|l|}{$T$-score (per SD) } \\
\hline Total hip & 459 & $0.92 \pm 0.15$ & -1.25 & 0.15 & $<0.001$ & -0.96 & 0.15 & $<0.001$ \\
\hline \multicolumn{9}{|l|}{$T$-score (per SD) } \\
\hline Lumbar spine & 459 & $1.03 \pm 0.21$ & -0.22 & 0.10 & 0.036 & -0.11 & 0.11 & 0.300 \\
\hline$T$-score (per SD) & & & & & & & & \\
\hline
\end{tabular}

Note: Relationship was determined by multivariable linear regression model (adjusted for: age, gender, BMI, smoking, hypertension, diabetes, hypercholesterolemia, and Cr). Abbreviations: BMD, bone mineral density; BMI, body mass index; $\mathrm{Cr}$, creatinine; $\mathrm{SE}$, standard error.

had osteoporosis, and 210 (130 men, 80 women) had osteopenia.

Catheterization data showed that 235 patients $(51.20 \%)$ had CAD, and 127 (27.67\%) had multivessel CAD as previously defined. Patient demographics are presented in Table 1 and were stratified according to non-CAD, one-vessel CAD, and multivessel CAD. There were significant differences for age, gender, smoking, hypertension, diabetes, serum creatinine (Cr), and modified Gensini score, with no significant difference for BMI and hypercholesterolemia, across the three groups. For BMD, significant difference was observed in regional area $\mathrm{BMD}\left(\mathrm{g} / \mathrm{cm}^{2}\right), T$-score (SD), and $Z$-score (SD), measured at total hip and femoral neck, but not at lumbar spine 1-4, among patients with non-CAD, one-vessel CAD, and multivessel CAD (Table 1). Minimum $T$-score (SD) of the three regions was also of significant difference, but not minimum $Z$-score (SD), for the three groups.

\section{Association between low BMD and multivessel CAD}

To evaluate the association of low BMD and multivessels $\mathrm{CAD}$, all parameters were first tested by univariable logistic regression analysis. The significant variables identified from univariable analysis included age, gender, smoking status, hypertension, hypercholesterolemia, diabetes, serum $\mathrm{Cr}$, and the value of BMD (Table S1). Previous studies suggested BMI was a strong correlate for BMD, and even if it was not associated with multivessel CAD in univariable analysis, it should be included in multiple logistic regression analysis. Multivariable logistic regression analysis showed that osteoporosis at femoral neck and total hip was associated with an increased risk of multivessel CAD (femoral neck, adjusted $\mathrm{OR}=4.34,95 \% \mathrm{CI}=2.05-9.20, P<0.001$; total hip, adjusted $\mathrm{OR}=2.91,95 \% \mathrm{CI}=1.29-6.60, P=0.0104)$, as was osteopenia (femoral neck, adjusted $\mathrm{OR}=2.84,95 \%$ $\mathrm{CI}=1.52-5.30, P=0.0011$; total hip, adjusted $\mathrm{OR}=2.55,95 \%$
$\mathrm{CI}=1.56-4.17, P<0.001)$. However, in multivariable logistic regression analysis, neither osteoporosis nor osteopenia at lumbar spine was related to the prevalence of multivessel CAD (Table 2). In addition, the relationship of low BMD and multivessels CAD was analyzed separately by gender, and the results were similar to those of the total patient group (Table S2).

\section{Association between BMD and the modified Gensini score of CAG}

Corresponding to the results of the univariable analysis (Table S1), multivariable linear regression analysis was used to detect the association between BMD and the modified Gensini score, and it was found that for every 1-unit increment in femoral neck and total hip $T$-score, the modified Gensini score decreased 1.13 and 0.96, respectively, after adjusting for factors including age, gender, BMI, smoking, hypertension, diabetes, hypercholesterolemia, and serum $\mathrm{Cr}$. However, no significant association between the BMD at lumbar spine 1-4 and the modified Gensini score was observed (Table 3). The same results were found when analyzed separately by gender (Table S3).

\section{Discussion}

Marcovitz et al showed the prevalence of angiographically diagnosed $\mathrm{CAD}$ ( $\geq 50 \%$ luminal stenosis in a major coronary artery) was significantly higher in patients with low BMD than in patients with normal BMD. ${ }^{20}$ The angiographic findings were considered to support the hypothesis that accelerated atherosclerosis links bone loss and increased future cardiovascular events and mortality. ${ }^{10}$ However, some subsequent studies in contrast found no association between low BMD and angiographically determined CAD either in women or men. ${ }^{11-14}$ The inconsistent results may be attributed to some important differences in methods of patient recruitment, sites and tools of BMD measurement, and ethnic group, but it did 
to some extent confuse our understanding of the relationship between bone loss and cardiovascular events.

However, angiographically diagnosed CAD just defines the luminal stenosis $\geq 50 \%$ or $70 \%$ of a coronary vessel, which does not depict global coronary atherosclerosis. Previous studies revealed the extent of atherosclerosis of the whole coronary tree rather than the severity of a coronary stenosis is a good predictor of future coronary events. ${ }^{16,21-25}$ Therefore, a description of global coronary atherosclerosis should be used instead of the prevalence of angiographically diagnosed CAD as an indicator to assess the relationship between BMD and coronary atherosclerosis in an angiographic study.

In the present study, we firstly demonstrated an association between low BMD (osteoporosis and/or osteopenia) and multivessel coronary disease (Table 2). This relationship remains significant after adjusting for age and other traditional coronary risk factors. The number of diseased coronary arteries is the simplest depiction of the global coronary atherosclerosis and has been proven a good predictor of long-term survival with sufficient evidence. ${ }^{25}$ The Coronary Artery Surgery Study (CASS) revealed that a 12-year survival rate for patients with zero-, one-, two-, and three-vessel disease was $88 \%, 74 \%, 59 \%$, and $40 \%$, respectively. ${ }^{22}$ A large population-based prospective cohort study also indicated that the survival rate of CAD patients was closely related to the extent of CAD and that patients with multivessel disease need coronary artery revascularization to obtain survival benefits. ${ }^{26}$ Based on these findings, we think the phenomenon that the low BMD predicting a high risk of CAD events, which is consistently verified in previous longitudinal cohort studies, now can be appropriately interpreted as the following: low BMD is correlated with more extensive coronary atherosclerosis, resulting in a higher risk of future coronary events.

Meanwhile, an analysis was performed on the relationship between the BMD and the modified Gensini score. The modified Gensini score is a well-known angiographic tool for grading the severity and extent of coronary atherosclerosis and assesses the diameter stenosis in an algorithmic methodology as $1 \%-49 \%, 50 \%-74 \%, 75 \%-99 \%$, and total occlusion. ${ }^{17,18}$ This angiographic scoring system provided a more detailed description of the global coronary atherosclerotic plaque burden than the number of diseased vessels which considers stenosis starting at a level of 50\% obstruction in the major epicardial vessels. The multivariable analysis revealed a significant correlation between the BMD values ( $T$-score) and the modified Gensini scores; it was shown that as $T$-scores (per SD) rose, the modified Gensini scores fell (Table 3).
A recently published article also showed that femur BMD values in patients with CAD decreased as their Gensini scores increased. ${ }^{27}$ In our study, the finding of an inverse relationship between the BMD and the modified Gensini score was in accordance with the increased risk of multivessel CAD in the low BMD group, suggesting that with the decrease of BMD values, the global coronary plaque burdens increased.

Although there is no consensus on which bone site best reflects bone health in relation to cardiovascular diseases, our findings and other studies consistently suggested hip BMD (femoral neck and the total hip) was a good predictor of atherosclerosis while lumbar spines are not. ${ }^{20,28-30}$ In the present study, there were no statistically significant associations between the modified scores and the BMD in lumbar spine $1-4$, and no effects of low BMD at lumbar spine 1-4 on risk of multivessel CAD. The lack of association with lumbar BMD may in part be attributed to degenerative changes in the lumbar spine in older adults, resulting in falsely elevated BMD levels and disguising the underlying osteoporosis..$^{29}$ Nevertheless, a profound mechanism relating low BMD to atherosclerosis needs to be considered to explain the phenomenon. For example, Bagger et al thought femur $\mathrm{BMD}$ reflected the atherosclerosis better than lumbar BMD, because the unilateral blood supply of the proximal femur was more vulnerable for deteriorating atherosclerosis than the bilateral blood supply of the vertebrae. ${ }^{10,28}$ It implied that the promotion of atherogenesis can contribute to bone loss, especially at skeletal sites with end-arterial blood supply.

However, the underlying mechanisms linking low BMD to atherosclerosis are complex and have not been fully understood. Other potential mechanisms have been discussed in literatures, which can be summarized as follows: Firstly, osteoporosis and atherosclerosis are common age-related disorders, sharing common traditional risk factors, such as current smoking status, alcohol use, diabetes, hypertension, estrogen deprivation, and hyperlipidemia. ${ }^{31}$ Secondly, there are some common pathological linkages during the progression of osteoporosis and atherosclerosis..$^{32,33}$ Thirdly, atherosclerotic disease might limit physical activity, leading to bone loss and osteoporosis.

\section{Study limitation}

The existing limitations of our study should be noted. First, this study reveals low BMD can predict increased risk of multivessel CAD, and inverse association between BMD and the extent of CAD; however, whether there is a causal relationship between the entities is not investigated due to the 
cross-sectional nature of the research. Second, the subjects enrolled in our trial were stable suspected CAD patients who were referred for a selective CAG. The study population might not represent the entire low BMD population, and thus, it is unknown if low BMD reflects the CAD morbidity among them.

\section{Conclusion}

The conflicting results from previous coronary angiographic studies have prompted us to reassess the relationship between BMD and coronary artery state with a more comprehensive perspective. This cross-sectional study elucidated an inverse relationship between hip BMD values ( $T$-scores) and global coronary atherosclerotic plaque burden, and low hip BMD weas significantly and independently associated with increased risk of multivessel coronary disease in patients hospitalized for stable chest pain. The findings in our study support the hypothesis that accelerated atherosclerosis links low BMD to cardiovascular events and mortality.

\section{Author contributions}

All authors contributed toward data analysis, drafting and revising the paper and agree to be accountable for all aspects of the work. All the authors have seen and approved the final version of the manuscript being submitted. The article is the authors' original work, has not been previously published, and is not under consideration for publication elsewhere.

\section{Disclosure}

The authors report no conflicts of interest in this work.

\section{References}

1. Mussolino ME, Madans JH, Gillum RF. Bone mineral density and mortality in women and men: the NHANES I epidemiologic follow-up study. Ann Epidemiol. 2003;13(10):692-697.

2. Samelson EJ, Kiel DP, Broe KE, et al. Metacarpal cortical area and risk of coronary heart disease: the Framingham Study. Am J Epidemiol. 2004;159(6):589-595.

3. TankoLB, Christiansen C, CoxDA, GeigerMJ, McNabbMA, Cummings SR. Relationship between osteoporosis and cardiovascular disease in postmenopausal women. J Bone Miner Res. 2005;20(11):1912-1920.

4. Farhat GN, Newman AB, Sutton-Tyrrell K, et al. The association of bone mineral density measures with incident cardiovascular disease in older adults. Osteoporos Int. 2007;18(7):999-1008.

5. Shen C, Deng J, Zhou R, et al. Relation between bone mineral density, bone loss and the risk of cardiovascular disease in a Chinese cohort. Am J Cardiol. 2012;110(8):1138-1142.

6. Chen SJ, Lin CS, Lin CL, Kao CH. Osteoporosis is associated with high risk for coronary heart disease: a population-based cohort study. Medicine (Baltimore). 2015;94(27):e11.

7. Parhami F, Garfinkel A, Demer LL. Role of lipids in osteoporosis. Arterioscler Thromb Vasc Biol. 2000;20(11):2346-2348.

8. McFarlane SI, Muniyappa R, Shin JJ, Bahtiyar G, Sowers JR. Osteoporosis and cardiovascular disease: brittle bones and boned arteries, is there a link? Endocrine. 2004;23(1):1-10.
9. Rajzbaum G, Bézie Y. Postmenopausal osteoporosis and atheroma. Joint Bone Spine. 2006;73(6):661-666.

10. Bagger YZ, Rasmussen HB, Alexandersen P, Werge T, Christiansen C, Tankó LB; PERF study group. Links between cardiovascular disease and osteoporosis in postmenopausal women: serum lipids or atherosclerosis per se? Osteoporos Int. 2007;18(4):505-512.

11. Beer S, Saely CH, Hoefle G, et al. Low bone mineral density is not associated with angiographically determined coronary atherosclerosis in men. Osteoporos Int. 2010;21(10):1695-1701.

12. Tekin GO, Kekilli E, Yagmur J, et al. Evaluation of cardiovascular risk factors and bone mineral density in post menopausal women undergoing coronary angiography. Int J Cardiol. 2008;131(1):66-69.

13. Iranpour $\mathrm{D}$, Pourbehi $\mathrm{M}$, Afroozandeh $\mathrm{M}$, et al. Bone mineral density is not related to angiographically diagnosed coronary artery disease. Hellenic J Nucl Med. 2014;17(2):111-115.

14. Hajsadeghi S, Khamseh ME, Larijani B, et al. Bone mineral density and coronary atherosclerosis. J Saudi Heart Assoc. 2011;23(3): 143-146.

15. Bonow RO, Mann DL, Zipes DP, Libby P, editors. Braunwald's Heart Disease: A Textbook of Cardiovascular Medicine. 9th ed. Philadelphia, PA: Saunders-Elsevier Health Sciences; 2012.

16. Ambrose JA, Fuster V. The risk of coronary occlusion is not proportional to the prior severity of coronary stenoses. Heart. 1998;79:3-4.

17. Adams MR, Nakagomi A, Keech A, et al. Carotid intima-media thickness is only weakly correlated with the extent and severity of coronary artery disease. Circulation. 1995;92(8):2127-2134.

18. Gensini GG. Coronary Angiography. Mount Kisco, NY: Futura Publishing Co; 1975.

19. Genant HK, Cooper C, et al. Interim report and recommendations of the World Health Organization Task-Force for Osteoporosis. Osteoporos Int. 1999;10(4):259-264.

20. Marcovitz PA, Tran HH, Franklin BA, et al. Usefulness of bone mineral density to predict significant coronary artery disease. Am J Cardiol. 2005;96(8):1059-1063.

21. Neeland IJ, Patel RS, Eshtehardi P, et al. Coronary angiographic scoring systems: an evaluation of their equivalence and validity. Am Heart $J$. 2012;164(4):547-552.

22. Emond M, Mock MB, Davis KB, et al. Long-term survival of medically treated patients in the Coronary Artery Surgery Study (CASS) Registry. Circulation. 1994;90(6):2645-2657.

23. Mark DB, Nelson CL, Califf RM, et al. Continuing evolution of therapy for coronary artery disease. Initial results from the era of coronary angioplasty. Circulation. 1994;89(5):2015-2025.

24. Califf RM, Armstrong PW, Carver JR, D'Agostino RB, Strauss WE. 27th Bethesda Conference: matching the intensity of risk factor management with the hazard for coronary disease events. Task Force 5. Stratification of patients into high, medium and low risk subgroups for purposes of risk factor management. J Am Coll Cardiol. 1996; 27(5):1007-1019.

25. Ringqvist I, Fisher LD, Mock M, et al. Prognostic value of angiographic indices of coronary artery disease from the Coronary Artery Surgery Study (CASS). J Clin Invest. 1983;71(6):1854-1866.

26. Hannan EL, Racz MJ, McCallister BD, Ryan TJ, Arani DT, Isom OW. A comparison of three-year survival after coronary artery bypass graft surgery and percutaneous transluminal coronary angioplasty. $J$ Am Coll Cardiol. 1999;33(1):63-72.

27. Alan B, Akpolat V, Aktan A, Alan S. Relationship between osteopenic syndrome and severity of coronary artery disease detected with coronary angiography and Gensini score in men. Clin Interv Aging. 2016;11:377-382.

28. Bagger YZ, Tanko LB, Alexandersen P, Qin G, Christiansen C; Prospective Epidemiological Risk Factors Study Group. Radiographic measure of aorta calcification is a site-specific predictor of bone loss and fracture risk at the hip. J Intern Med. 2006;259(6):598-605. 
29. Kinoshita H, Tamaki T, Hashimoto T, Kasagi F. Factors influencing lumbar spine bone mineral density assessment by dual-energy X-ray absorptiometry: comparison with lumbar spinal radiogram. JOrthop Sci. 1998;3(1):3-9.

30. Pinheiro MM, Castro CM, Szejnfeld VL. Low femoral bone mineral density and quantitative ultrasound are risk factors for new osteoporotic fracture and total and cardiovascular mortality: a 5-year populationbased study of Brazilian elderly women. J Gerontol A Biol Sci Med Sci. 2006;61(2):196-203.
31. Crepaldi G, Maggi S. Epidemiologic link between osteoporosis and cardiovascular disease. J Endocrinol Invest. 2009;32(4 Suppl):2-5.

32. Lello S, Capozzi A, Scambia G. Osteoporosis and cardiovascular disease: an update. Gynecol Endocrinol. 2015;31(8):590-594.

33. Hamerman D. Osteoporosis and atherosclerosis: biological linkages and the emergence of dual-purpose therapies. QJM. 2005;98(7):467-484. 


\section{Supplementary materials}

Table SI Univariable analysis for multivessel CAD and modified Gensini score

\begin{tabular}{|c|c|c|c|c|c|c|}
\hline \multirow[t]{3}{*}{ Parameters } & \multirow{3}{*}{$\begin{array}{l}\text { Non-CAD } \\
\mathrm{n}=224\end{array}$} & \multicolumn{2}{|l|}{ CAD } & \multirow{3}{*}{$\begin{array}{l}\text { ANOVA } \\
\text { P-value }\end{array}$} & Multivessel & Modified \\
\hline & & \multirow{2}{*}{$\begin{array}{l}\text { One-vessel } \\
(n=108)\end{array}$} & \multirow{2}{*}{$\begin{array}{l}\text { Multivessel } \\
(n=\mid 27)\end{array}$} & & \multicolumn{2}{|c|}{ Univariable analysis } \\
\hline & & & & & $P$-value & $P$-value \\
\hline Age (years) & $62.03 \pm 10.16$ & $65.93 \pm 9.16$ & $68.47 \pm 8.12$ & $<0.001$ & $<0.001$ & $<0.001$ \\
\hline Men, n (\%) & 105 (46.88\%) & $6 \mathrm{I}(56.48 \%)$ & $8 \mathrm{I}(63.78 \%)$ & 0.008 & 0.008 & 0.045 \\
\hline BMI $\left(\mathrm{kg} / \mathrm{m}^{2}\right)$ & $24.26 \pm 3.35$ & $24.92 \pm 3.78$ & $24.36 \pm 3.14$ & 0.242 & 0.747 & 0.169 \\
\hline Smoker, n (\%) & $62(27.68 \%)$ & $4 \mathrm{l}(37.96 \%)$ & $62(48.82 \%)$ & $<0.001$ & $<0.001$ & 0.003 \\
\hline Hypertension, n (\%) & $139(62.05 \%)$ & $82(75.93 \%)$ & 107 (84.25\%) & $<0.001$ & $<0.001$ & $<0.00 \mathrm{I}$ \\
\hline Diabetes & 40 (17.86\%) & $28(25.93 \%)$ & $44(34.65 \%)$ & 0.002 & 0.002 & 0.007 \\
\hline Hypercholesterolemia, n (\%) & $57(25.45 \%)$ & $29(26.85 \%)$ & $43(33.86 \%)$ & 0.229 & 0.091 & 0.005 \\
\hline $\mathrm{Cr}(\mu \mathrm{mol} / \mathrm{L})$ & $73.56 \pm 23.29$ & $78.54 \pm 26.33$ & $84.28 \pm 40.86$ & 0.005 & 0.008 & $<0.00$ I \\
\hline Modified Gensini score & $5.26 \pm 1.27$ & $7.93 \pm 1.42$ & $12.26 \pm 3.62$ & $<0.001$ & NA & NA \\
\hline Femoral neck $\left(\mathrm{g} / \mathrm{cm}^{2}\right)$ & $0.86 \pm 0.15$ & $0.84 \pm 0.15$ & $0.79 \pm 0.13$ & $<0.001$ & $<0.001$ & $<0.001$ \\
\hline Femoral neck $T$-score (SD) & $-1.33 \pm 1.08$ & $-1.57 \pm 0.99$ & $-2.03 \pm 0.93$ & $<0.00 \mathrm{I}$ & $<0.001$ & $<0.001$ \\
\hline Total hip $\left(\mathrm{g} / \mathrm{cm}^{2}\right)$ & $0.95 \pm 0.15$ & $0.92 \pm 0.16$ & $0.87 \pm 0.14$ & $<0.00 \mathrm{I}$ & $<0.001$ & $<0.001$ \\
\hline Total hip T-score (SD) & $-0.75 \pm 1.07$ & $-0.99 \pm 1.05$ & $-1.43 \pm 0.97$ & $<0.00 \mathrm{I}$ & $<0.001$ & $<0.00$ I \\
\hline Lumbar spine $\mathrm{I}-4\left(\mathrm{~g} / \mathrm{cm}^{2}\right)$ & $1.04 \pm 0.20$ & $1.02 \pm 0.22$ & $\mathrm{I} .0 \mathrm{I} \pm 0.2 \mathrm{I}$ & 0.567 & 0.347 & 0.079 \\
\hline Lumbar spine $T$-score (SD) & $-1.33 \pm 1.6 \mid$ & $-1.48 \pm 1.73$ & $-1.58 \pm 1.65$ & 0.380 & 0.246 & 0.036 \\
\hline
\end{tabular}

Notes: Values are presented as means \pm SD. Percentages do not sum to 100 because of rounding.

Abbreviations: ANOVA, analysis of variance; BMI, body mass index; CAD, coronary artery disease; $\mathrm{Cr}$, creatinine; NA, not available.

Table S2 Association between low BMD at various skeletal regions and multivessel CAD

\begin{tabular}{|c|c|c|c|c|c|c|c|c|}
\hline \multirow{2}{*}{$\frac{\text { Variables }}{\text { BMD }}$} & \multirow[t]{2}{*}{$\mathbf{n}$} & \multirow{2}{*}{$\begin{array}{l}\text { Mean } \pm \text { SD } \\
\left(\mathrm{g} / \mathrm{cm}^{2}\right)\end{array}$} & \multicolumn{3}{|c|}{ Crude } & \multicolumn{3}{|c|}{ Adjusted } \\
\hline & & & OR & $95 \% \mathrm{Cl}$ & $P$-value & OR & $95 \% \mathrm{Cl}$ & $P$-value \\
\hline \multicolumn{9}{|l|}{ Multivessel CAD vs non-multivessel CAD } \\
\hline \multicolumn{9}{|l|}{ Gender=women } \\
\hline Femoral neck & 212 & $0.78 \pm 0.13$ & & & & & & \\
\hline Normal (T-score $\geq-1.0 \mathrm{SD})$ & 45 & $0.96 \pm 0.05$ & I & & & I & & \\
\hline Osteopenia ( $T$-score -1.0 to $-2.5 \mathrm{SD})$ & 106 & $0.79 \pm 0.05$ & 3.88 & $1.10-13.66$ & 0.0348 & 3.67 & $0.94-14.30$ & 0.0607 \\
\hline Osteoporosis ( $T$-score $\leq-2.5 \mathrm{SD})$ & 61 & $0.63 \pm 0.06$ & 6.83 & $1.88-24.75$ & 0.0034 & 4.84 & I. I4-20.43 & 0.032 \\
\hline Total hip & 212 & $0.86 \pm 0.14$ & & & & & & \\
\hline Normal ( $T$-score $\geq-1.0 \mathrm{SD})$ & 98 & $0.98 \pm 0.09$ & I & & & I & & \\
\hline Osteopenia ( $T$-score -1.0 to $-2.5 \mathrm{SD})$ & 81 & $0.8 \mathrm{I} \pm 0.06$ & 3.93 & $1.75-8.80$ & 0.0009 & 2.70 & $1.12-6.52$ & 0.0275 \\
\hline Osteoporosis ( $T$-score $\leq-2.5 \mathrm{SD})$ & 33 & $0.65 \pm 0.04$ & 4.4 & $1.66-11.67$ & 0.0029 & 3.15 & $0.98-10.15$ & 0.0544 \\
\hline Lumbar spine & 212 & $0.92 \pm 0.17$ & & & & & & \\
\hline Normal ( $T$-score $\geq-I .0 \mathrm{SD})$ & 43 & $1.18 \pm 0.11$ & I & & & 1 & & \\
\hline Osteopenia ( $T$-score -1.0 to $-2.5 \mathrm{SD})$ & 71 & $0.96 \pm 0.06$ & 1.39 & $0.45-4.32$ & 0.5659 & 1.2 & $0.35-4.05$ & 0.7706 \\
\hline Osteoporosis (T-score $\leq-2.5 \mathrm{SD})$ & 98 & $0.78 \pm 0.08$ & 3.35 & $1.20-9.36$ & 0.0209 & 2.32 & $0.75-7.20$ & 0.1453 \\
\hline \multicolumn{9}{|l|}{ Gender=men } \\
\hline Femoral neck & 247 & $0.88 \pm 0.14$ & & & & & & \\
\hline Normal ( $T$-score $\geq-1.0$ SD) & 84 & $1.02 \pm 0.12$ & I & & & I & & \\
\hline Osteopenia ( $T$-score -1.0 to $-2.5 \mathrm{SD})$ & 130 & $0.84 \pm 0.06$ & 2.93 & I.49-5.75 & 0.0018 & 2.61 & $1.29-5.28$ & 0.0078 \\
\hline Osteoporosis ( $T$-score $\leq-2.5 \mathrm{SD})$ & 33 & $0.68 \pm 0.07$ & 6.79 & $2.77-16.65$ & $<0.0001$ & 5.08 & $1.97-13.13$ & 0.0008 \\
\hline Total hip & 247 & $0.97 \pm 0.15$ & & & & & & \\
\hline Normal ( $T$-score $\geq-1.0 \mathrm{SD})$ & 136 & $1.07 \pm 0.12$ & I & & & I & & \\
\hline Osteopenia ( $T$-score -1.0 to $-2.5 \mathrm{SD})$ & 101 & $0.87 \pm 0.05$ & 2.84 & $1.62-4.99$ & 0.0003 & 2.46 & $1.36-4.45$ & 0.0028 \\
\hline Osteoporosis (T-score $\leq-2.5 \mathrm{SD})$ & 10 & $0.70 \pm 0.06$ & 5.3 & I.40-20.0। & 0.0139 & 4.26 & $1.05-17.37$ & 0.0432 \\
\hline
\end{tabular}


Table S2 (Continued)

\begin{tabular}{|c|c|c|c|c|c|c|c|c|}
\hline \multirow{2}{*}{$\begin{array}{l}\text { Variables } \\
\text { BMD } \\
\end{array}$} & \multirow[t]{2}{*}{$\mathbf{n}$} & \multirow{2}{*}{$\begin{array}{l}\text { Mean } \pm \text { SD } \\
\left(\mathrm{g} / \mathrm{cm}^{2}\right)\end{array}$} & \multicolumn{3}{|c|}{ Crude } & \multicolumn{3}{|c|}{ Adjusted } \\
\hline & & & OR & $95 \% \mathrm{Cl}$ & $P$-value & OR & $95 \% \mathrm{Cl}$ & $P$-value \\
\hline Lumbar spine & 247 & $1.12 \pm 0.19$ & & & & & & \\
\hline Normal ( $T$-score $\geq-1.0$ SD) & $|3|$ & $1.25 \pm 0.14$ & 1 & & & I & & \\
\hline Osteopenia ( $T$-score -1.0 to $-2.5 \mathrm{SD})$ & 84 & $1.02 \pm 0.06$ & 1.33 & $0.75-2.37$ & 0.3331 & 1.16 & $0.63-2.15$ & 0.6347 \\
\hline Osteoporosis ( $T$-score $\leq-2.5 \mathrm{SD})$ & 32 & $0.83 \pm 0.07$ & $\mathrm{I} .03$ & $0.45-2.38$ & 0.9373 & 0.82 & $0.33-2.02$ & 0.665 \\
\hline
\end{tabular}

Notes: Relationship was determined by multivariable logistic regression analysis by gender (adjusted for: age, gender, BMI, hypertension, diabetes, hypercholesterolemia, and $\mathrm{Cr}$ ). Multivessel CAD was defined as luminal stenosis $\geq 50 \%$ in two or more vessels.

Abbreviations: BMD, bone mineral density; BMI, body mass index; CAD, coronary artery disease; $\mathrm{Cr}$, creatinine.

Table S3 Association between T-score at various skeletal regions and the modified Gensini score

\begin{tabular}{|c|c|c|c|c|c|c|c|c|}
\hline \multirow{2}{*}{$\begin{array}{l}\text { Variables } \\
\text { BMD }\end{array}$} & \multirow[t]{2}{*}{$\mathbf{n}$} & \multirow{2}{*}{$\begin{array}{l}\text { Mean } \pm \text { SD } \\
\left(\mathrm{g} / \mathrm{cm}^{2}\right)\end{array}$} & \multicolumn{3}{|c|}{ Crude } & \multicolumn{3}{|c|}{ Adjusted } \\
\hline & & & $\beta$ & SE & $P$-value & $\beta$ & SE & $P$-value \\
\hline \multicolumn{9}{|l|}{ Gender=women } \\
\hline Femoral neck $T$-score (per SD) & 212 & $0.78 \pm 0.13$ & -1.31 & 0.21 & $<0.0001$ & -0.82 & 0.24 & 0.0006 \\
\hline Total hip T-score (per SD) & 212 & $0.86 \pm 0.14$ & -1.23 & 0.19 & $<0.0001$ & -0.84 & 0.22 & 0.0001 \\
\hline Lumbar spine $T$-score (per SD) & 212 & $0.92 \pm 0.17$ & -0.55 & 0.16 & 0.0008 & -0.18 & 0.16 & 0.2667 \\
\hline \multicolumn{9}{|l|}{ Gender $=$ men } \\
\hline Femoral neck $T$-score (per SD) & 247 & $0.88 \pm 0.14$ & -1.67 & 0.21 & $<0.0001$ & -1.43 & 0.21 & $<0.0001$ \\
\hline Total hip T-score (per SD) & 247 & $0.97 \pm 0.15$ & -1.43 & 0.23 & $<0.0001$ & -1.25 & 0.22 & $<0.0001$ \\
\hline Lumbar spine $T$-score (per SD) & 247 & $1.12 \pm 0.19$ & -0.25 & 0.16 & 0.1151 & -0.15 & 0.15 & 0.3089 \\
\hline
\end{tabular}

Note: Relationship was determined by multivariable linear regression analysis by gender (adjusted for: age, gender, BMI, smoking, hypertension, diabetes, hypercholesterolemia, and $\mathrm{Cr}$ ).

Abbreviations: BMD, bone mineral density; BMI, body mass index; $\mathrm{Cr}$, creatinine.

\section{Publish your work in this journal}

Clinical Interventions in Aging is an international, peer-reviewed journal focusing on evidence-based reports on the value or lack thereof of treatments intended to prevent or delay the onset of maladaptive correlates of aging in human beings. This journal is indexed on PubMed Central, MedLine,
CAS, Scopus and the Elsevier Bibliographic databases. The manuscript management system is completely online and includes a very quick and fair peer-review system, which is all easy to use. Visit http://www.dovepress. $\mathrm{com} /$ testimonials.php to read real quotes from published authors. 